Traditional Medicine and Modern Medicine

Vol. 2, No. 1 (2019) 27-29

(C) Institutes of Integrative Medicine, Fudan University and

World Century Publishing Corporation

DOI: $10.1142 / \mathrm{S} 2575900019500058$

\title{
Efficiency of immunomodulatory therapy in the complex treatment of patients with combined craniofacial injuries
}

\author{
D. D. Ibragimov and Shuhrat A. Boymuradov* \\ Samarkand State Medical Institute, 18 Amir Timur Street \\ 140100 Samarkand City, Republic of Uzbekistan \\ Tashkent Medical Academy, 2 Faroby Street \\ 100109 Tashkent, Republic of Uzbekistan \\ *Shuh69@mail.ru
}

Received 19 December 2018; Accepted 21 February 2019; Published 31 May 2019

\begin{abstract}
Background: Our aim is to study the effectiveness of immunomodulatory therapy with Polyoxidonium in the complex treatment of patients with combined craniofacial injuries.

Methods: In accordance with the intended purpose of this study, we conducted a comprehensive immunological examination of patients with combined craniofacial injuries in the dynamics of treatment with the drug authorized for use in healthcare practice: Polyoxidonium. In total 22 patients with combined craniofacial injuries in the complex therapy received Polyoxidonium at a dosage level of $6 \mathrm{mg} / \mathrm{m}$ once for 5 days.

Results: We conducted a comprehensive immunological study of the clinical course of the post-traumatic period in patients with combined craniofacial injuries which showed that the immunomodulatory therapy with Polyoxidonium during the complex treatment has a high clinical and immunological efficacy.

Conclusions: Thus, in patients with combined craniofacial injuries, there is an immunodeficiency state involving both cellular immunity, manifested by a decrease in the level of T-lymphocytes, T-helpers, NK-cells and Blymphocytes, and decrease of immunoglobulin production. The use of Polyoxidonium immunomodulator in complex therapy in patients with combined craniofacial injuries helped in improving the condition of patients in a shorter period of time and in preventing the development of purulent-inflammatory complications due to the positive dynamics of cellular and humoral immunity.
\end{abstract}

Keywords: Craniofacial injuries; post-traumatic period; Polyoxidonium; immunomodulatory therapy.

\section{Introduction}

In the last decade there has been a clear trend of increasing injuries, especially combined craniofacial injuries (CCLT). Thus, according to the literature, the frequency of combined craniofacial injuries is from $2.9 \%$ to $42.6 \% .^{2-4,9}$ Despite significant progress, treatment of patients with injuries of the bones of the craniofacial skeleton and prevention of complications is a difficult and far from solved problem of modern maxillofacial surgery. The severity is due to, on the one hand, the problem of quality and speed of bone regenerate formation, suffering as a result of traumatism, and, on the other hand, traumatic complications, among which the most important in terms of frequency and severity are the complications of purulent-inflammatory nature, reaching $30 \%$. $^{6-9}$ The immune system takes a certain role in the development of bone tissue regeneration and prevention of pyoinflammatory complications. ${ }^{5,10}$ In this context, of great importance is the development of new approaches to optimize the treatment of patients affected by the trauma of craniofacial skeleton injuries, one among which is the inclusion in the scheme of complex therapy of immunomodulatory drugs. There seems to be a promising application of

*Corresponding author. 
the immunomodulator Polyoxidonium (bromide anoxemia) - an $N$-oxidized derivative of polyethylene-piperazine with a wide spectrum of pharmacological effects on the body: Immunomodulatory-conductive, detoxifying, antioxidant and membrane-protective effects. The immunomodulatory effect is to increase the ability of neutrophils to absorb and kill the foreign body; to enhance the cytotoxic activity of NK-cells; to activate resident macrophages of the reticuloendothelial system, which leads to a more rapid elimination of foreign particles from the body; to increase the natural resistance of the body against experimental bacterial and viral infections; to remove antibody-dependent and T-independent antigens of both animal and bacterial origins. Detoxifying properties of Polyoxidonium are associated with its high molecular weight and the presence on the surface of the molecule of a large number of different active groups. Antioxidant properties of Polyoxidonium are manifested in the interception of reactive oxygen species (superoxide anion, hydrogen peroxide, hydroxyl radical) in the aqueous medium and in the reduction of the concentration of catalyticallyactive ferrous iron, which leads to the suppression of lipid peroxidation..$^{1,7,9}$

The aim of this study is to study the effectiveness of immunomodulatory therapy with Polyoxidonium in the complex treatment of patients with combined craniofacial injuries.

\section{Material and Methods}

In accordance with the intended purpose of this study, we conducted a comprehensive immunological examination of patients with combined craniofacial injuries in the dynamics of treatment with the drug authorized for use in healthcare practice: Polyoxidonium. In total 22 patients with combined craniofacial injuries in the complex therapy received Polyoxidonium at a dosage level of $6 \mathrm{mg} / \mathrm{m}$ once for 5 days. Clinical and immunological examinations were carried out at the time of admission and on the 10th day after the start of treatment. Examination and treatment of patients were carried out at the Department of Maxillofacial Surgery of Samarkand State Medical Institute. Clinical studies were conducted according to the standard scheme and included a survey of patients, the collection of anamnesis, anamnesis of life, physical methods (examination, palpation, percussion), laboratory and instrumental additional research methods (general analysis of blood and urine, if necessary, biochemical blood tests, X-ray examination of the bones of the facial skeleton and skull) as well as an expert advice (neurosurgeon, otorhinolaryngologist, ophthalmologist, traumatologist, anesthesiologist). Immunological methods included the following: immunophenotyping of cells $(\mathrm{CD} 3+, \mathrm{CD} 4+, \mathrm{CD} 8+, \mathrm{CD} 16+, \mathrm{CD} 19+$ lymphocytes) with monoclonal antibodies, serum concentrations of immunoglobulins of classes A, M and G were measured by enzyme immunoassay.

Statistical processing of the results was carried out by programs developed in EXCEL using a library of statistical functions with the calculation of the arithmetic mean $(M)$, the error of the arithmetic mean $(m)$, performing the Student's $t$-test and calculation of the probability of error $(p)$.

\section{Results}

The study of the features of the clinical course of the posttraumatic period in patients with combined craniofacial injuries showed that the immunomodulatory therapy with Polyoxidonium in the complex treatment has a high clinical and immunological efficacy.

Thus, when including Polyoxidonium in the treatment regimen, stabilization of the general condition of patients occurs faster, and there is a more rapid regression of systemic and local manifestations of inflammatory post-traumatic reaction. Normalization of temperature occurred 2-3 days after the start of immunomodulatory therapy of patients against 5-6 days after traditional treatment $(p<0.001)$. The dynamics of the decrease in the severity of the syndrome of general intoxication and the disappearance of its clinical manifestations in the group receiving immunomodulatory therapy with Polyoxidonium were clearly observed. Control of general clinical parameters of peripheral blood allowed to state earlier normalization when Polyoxidonium is included in the treatment regimen. It should be noted that in the group of patients receiving immunomodulatory therapy with Polyoxidonium, no patient developed a purulent-inflammatory complication.

The study of the immune status of patients with combined craniofacial injuries revealed patterns of immune response, expressed as a deficiency of $\mathrm{CD} 3+, \mathrm{CD} 4+, \mathrm{CD} 8+$ cells. That CD19+ with depression of production of IDA and IgG at relatively close to normal values of the number of $\operatorname{IgM}$, was the basis for the development of a method of correction of immune disorders with the inclusion of Polyoxidonium in the scheme of traditional therapy in patients with CCLT. So, in the second group which received Polyoxidonium, $\mathrm{CD} 3+, \mathrm{CD} 4+, \mathrm{CD} 8+$ and $\mathrm{CD} 16+$ in peripheral blood increased. Thus, patients of the second group had an increase in the level of T-lymphocytes $[(55.1 \pm 0.21) \%$ versus $(47.9 \pm 0.41) \%$ before treatment; $p<0.05]$ due to an increase in the levels of CD4+ lymphocytes [ $(37.4 \pm 0.32) \%$ versus $(29.6 \pm 0.23) \%$ prior to treatment], CD8+ lymphocytes $[(23.0 \pm 0.24) \%$ versus $(18.1 \pm 0.12) \%$ before the treatment] and CD16+ lymphocytes $[(17.4 \pm 0.31) \%$ versus $(16.4 \pm 0.39) \%$ prior to treatment]; see Table 1 . 
Table 1. Cell components (in \%) of IP patients with CCLT.

\begin{tabular}{|c|c|c|c|c|}
\hline \multirow[b]{2}{*}{ Indicators of IP } & \multirow[b]{2}{*}{ Control group } & \multirow[b]{2}{*}{ Original value } & \multirow{2}{*}{$\frac{\text { Traditional treatment }}{\text { Group } 1}$} & \multirow{2}{*}{$\frac{\text { Traditional treatment }+ \text { Polyoxidonium }}{\text { Group } 2}$} \\
\hline & & & & \\
\hline $\mathrm{CD} 3+(\%)$ & $(56.4 \pm 0.57)$ & $(47.9 \pm 0.41)^{\mathrm{b}}$ & $(49.7 \pm 1.05)$ & $(55.1 \pm 0.21)^{\mathrm{a}}$ \\
\hline $\mathrm{CD} 4+(\%)$ & $(35.5 \pm 0.37)$ & $(29.6 \pm 0.23)^{b}$ & $(32.7 \pm 0.54)^{\mathrm{a}}$ & $(37.4 \pm 0.32)^{\mathrm{a}}$ \\
\hline $\mathrm{CD} 8+(\%)$ & $(19.1 \pm 0.31)$ & $(18.1 \pm 0.12)$ & $(18.7 \pm 0.84)$ & $(23.0 \pm 0.24)^{\mathrm{a}}$ \\
\hline CD16+(\%) & $(18.1 \pm 0.74)$ & $(16.4 \pm 0.39)^{\mathrm{b}}$ & $(16.9 \pm 0.85)$ & $(17.4 \pm 0.31)^{\mathrm{a}}$ \\
\hline
\end{tabular}

Note: ${ }^{\mathrm{a}} p<0.05$ treatment; ${ }^{\mathrm{b}} p<0.05$ control.

Table 2. Indicators of humoral immunity (in $\mathrm{mg} \%$ ) of IP patients with CCLT.

\begin{tabular}{lccccc}
\hline & & & Traditional treatment & & Traditional treatment + Polyoxidonium \\
\cline { 5 - 6 } Indicators of IP & Control group & Original value & Group 1 & & Group 2 \\
\hline CD19+ (mg\%) & $(22.1 \pm 0.3)$ & $(18.1 \pm 0.37)^{\mathrm{b}}$ & $(18.7 \pm 0.41)$ & $(21.9 \pm 0.67)^{\mathrm{a}}$ \\
IgA $(\mathrm{mg} \%)$ & $(188.4 \pm 11.5)$ & $(137.7 \pm 7.1)^{\mathrm{b}}$ & & $(139.7 \pm 4.2)^{\mathrm{b}}$ & $(161.7 \pm 9.91)^{\mathrm{a}}$ \\
IgM $(\mathrm{mg} \%)$ & $(111.2 \pm 4.47)$ & $(122.3 \pm 6.4)$ & & $(118.1 \pm 2.1)$ & $(132.5 \pm 8.1)^{\mathrm{b}}$ \\
IgG $(\mathrm{mg} \%)$ & $(997.7 \pm 24.4)$ & $(901.2 \pm 47.8)^{\mathrm{b}}$ & $(1004.2 \pm 31.7)$ & & $(1061.7 \pm 17.4)^{\mathrm{a}}$ \\
\hline
\end{tabular}

Note: ${ }^{\mathrm{a}} p<0.05$ treatment; ${ }^{\mathrm{b}} p<0.05$ control.

In the study of the dynamics of humoral immunity against the background of complex therapy with immunomodulator Polyoxidonium, the tendency to normalization of the humoral immunity was observed: normalization of the level of $\mathrm{CD} 19+$ to control values, increase in the levels of $\operatorname{IgA}$, IgM and IgG. Patients of the second group showed an increase in the level of B-lymphocytes to $(21.9 \pm 0.67) \%$ versus the $(18.1 \pm 0.37) \%$ before treatment $(p<0.05)$; see Table 2 .

The clinical and immunological data obtained by us showed the advantages of the inclusion of immunomodulator in the complex treatment of patients with combined craniofacial injuries; and they clearly showed that the positive dynamics of changes in immunological parameters in patients directly correlated with the clinical course of the disease.

Thus, in patients with combined craniofacial injuries, there is an immunodeficiency state involving cellular immunity, manifested by a decrease in the levels of T-lymphocytes, T-helpers, NK-cells and B-lymphocytes with the decrease of immunoglobulin production. The use of Polyoxidonium immunomodulator in complex therapy in patients with combined craniofacial injuries allowed to improve the condition of patients in a shorter period of time and to prevent the development of purulent-inflammatory complications due to the positive dynamics of cellular and humoral immunity.

\section{References}

1. Yermolov AS, Hubutiya MSh, Abakumov MM, eds. An Abdominal Trauma. Moscow, 2010:504.

2. Boymuradov Sh.A. Combined craniofacial trauma. Proceedings of the Collection of the Republican Scientific and Practical Conference with the International Participation "Topical Issues of Stomatology". Bukhara, 2012:25-26.

3. Boymuradov Sh.A. Treatment of patients with the combined injury of bones of the person. Moscow, 2014:227.

4. Boymuradov Sh.A. Innovative methods of treatment of the combined injuries of bones of facial skeleton on the basis of algorithmization of activity of the doctor. Probl Biol Med 2014; (1):28-33.

5. Bulava GB, Nikulina VP. Marks of efficiency of immunomodulators at treatment of patients with it is purulent: Septic postoperative complications. Surgery 2006;(2):104-107.

6. Haitov RM, Pinegin BV. Modern immunomodulators: Basic principles of their application. Immunology 2000;(5):4-7.

7. Haitov RM, Pinegin BV. Immunomodulators: Mechanism of action and clinical application. Immunology 2003;(4):196203.

8. Kabanova SA. Indicators of the immune status at severe forms of pyoinflammatory processes of maxillofacial area. Russ Dental Mag 2009;(3):36-39.

9. Sitnikov VN. Diagnostics and treatment of injuries of a stomach at the isolated and combined trauma. Doctoral dissertation, Rostov-on-Don, 2006:42.

10. Volozhin AI. A role of reactivity of an organism in the choice of strategy and tactics of treatment of sharp inflammatory processes in maxillofacial area. Stomatology 1996;(5):49. 